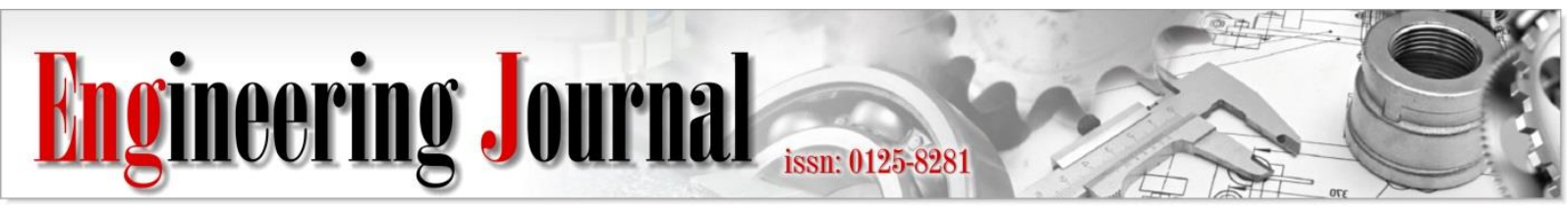

Article

\title{
Logistic Regression Analysis of Factors Affecting Travel Mode Choice for Disaster Evacuation
}

\author{
Thanawan Phiophuead ${ }^{\mathrm{a}}$ and Nipawan Kunsuwan ${ }^{\mathrm{b}, *}$ \\ Department of Civil Engineering, Faculty of Engineering at Kamphaeng Saen, Kasetsart University, \\ Nakhon Pathom 73140, Thailand \\ E-mail: athanawan.phio@ku.th, bfengnpw@ku.ac.th (Corresponding author)
}

\begin{abstract}
The relationships were analyzed among the factors affecting the travel mode choice between government vehicles and private vehicles used for the evacuation of people in areas experiencing floods and landslides. The relationships were developed using a utility function to predict the probability and proportion for selection of the travel mode in future evacuations based on binary logistic regression. Three models were developed using different analytical factors based on the survey data of a sample group of people in the Mae Pong watershed, Laplae district, Uttaradit province, Thailand. It was found that the factors affecting the selection of travel mode in all three models consisted of sex, household size, families with young members, education, car ownership, experienced a disaster, recognition of shelter location, safety of evacuees while evacuating, reaching the destination quickly, convenience of vehicle access, proportional family management for evacuation, ease of the evacuation procedures of mode, and difference between travel time and walking time to the assembly point. Models 1, 2, and 3 could predict with accuracies of 78.40, 73.46, and 75.30 percent, respectively.
\end{abstract}

Keywords: Modal split, migration, binary logistic regression, victim, hazard.

ENGINEERING JOURNAL Volume 23 Issue 6

Received 9 June 2019

Accepted 28 October 2019

Published 30 November 2019

Online at http://www.engj.org/

DOI:10.4186/ej.2019.23.6.399 


\section{Introduction}

The current trend is expected to continue for more frequent occurrences of global natural disasters. Natural disasters have an extensive effect on life, property and social, economic, and environmental factors and these disasters are also difficult to predict. Therefore, it is necessary to monitor the management of disasters and planning for emergencies in areas at risk of disaster. [1] The Mae Pong watershed, Laplae district, Uttaradit province is located in northern Thailand and has 3,276 inhabitants and 1,346 households. The majority of the population practices agriculture (orchards). The terrain is forested and mountainous with the center of the area on a plain, which is the main source of water. This area disaster risks associated with flooding, landslides, fire, and drought, which can all cause loss of life and property. [2] The statistics on disaster occurrence for 2006 indicated there were disastrous floods and landslides, resulting in 83 deaths, 33 missing, and 673 houses damaged.

When a disaster occurs, the victims are often unable to continue living in their residences, so they have to evacuate to temporary shelter. The two common modes of travel that people select for evacuation are government vehicles and private vehicles. This can result in more vehicles on the roads trying to evacuate the disaster area than the capacity of the roads, resulting in traffic congestion which delays evacuation to temporary shelter. Encouraging people to choose to evacuate by government vehicles rather than private vehicles can help to reduce the number of vehicles on the road.

Although decision-making on evacuation has been considered as an important issue, the logistic principles related to the specific disaster occurrence should be taken into account to understand the major factors affecting victims' decision [3]. Selecting an appropriate travel mode choice is one of the main tasks according to logistic principles in order to accomplish successful evacuation. As such, the objectives of this research were: 1) to investigate factors affecting the travel model choice between government vehicles and private vehicles and 2) to create a model that can be used to predict the proportion by travel model chosen for a future evacuation. Model analysis used binary logistic regression to represent the relationships among the factors affecting the travel model choice, where these relationships were expressed in terms of utility functions. Thus, this research can contribute to government agencies planning the evacuation of victims and preparing vehicles for evacuation in accordance with the behavior and satisfaction of the people in selecting the travel mode. This can help to reduce traffic congestion at the time of evacuation, making it possible to manage evacuations more quickly and securely.

This paper is organized as follows. The next section introduces the factors influencing mode choice that were collected to assist in designing the survey questionnaire. The section on utility function and the logistic regression model describes the theory on which the analysis was based. The research methodology section provides details for the questionnaire design guidelines and model analysis procedure. Then, the results of the research are presented followed by a final section that presents the conclusions.

\section{Factors Influencing Travel Mode Choice}

This study collected information on the necessary factors that influence the selection of travel mode from related articles and the literature as follows.

Zubair et.al [4] surveyed the opinions of public system users in Karachi, Pakistan regarding buses and minibuses to improve effective operational public transportation modes. The details of the survey comprised several factors that affected satisfaction such as capacity, safety, purpose of travel, seating arrangement, bus conditions, bus operations, bus stops, distance between the destination and bus stops, existing fare, time saving, and vehicle ownership.

Nguonsong and Kasem [5] investigated the factors that influenced the frequency of using informal transport and public buses in Phnom Penh, Cambodia by considering travelers' socioeconomic factors (gender, age, occupation, education, and income, among others), trip characteristics (travel time, cost, and distance), and the operational characteristics of each transport mode.

Wachs [6] surveyed the attitudes of travelers regarding the transit system to suggest policy for improving the transportation service in directions most consistent with travelers' perceptions. Traveler attitudes factors were reviewed such as travel time, reliability, convenience, comfort, safety, cost, and amenity of transit service.

Tuan and MateoBabiano [7] studied characteristics of the motorcycle taxi service in Vietnam to suggest regulations necessary for effectively managing and improving the future service. The collected questionnaire included users' characteristics (such as occupation, income, trip purpose, frequency, and trip distance), 
operational characteristics, and service perceptions (door-to-door service, easily accessible, fast, and flexible transport services).

Chaiwong and Siradon [8] developed a binary logistic regression model to predict the parents' possibility of getting their children to use the Kiss and Ride facility in downtown Nakhon Ratchasima province, Thailand. The survey was conducted using factors consisting of travel time, distance, and parent's socioeconomic characteristics.

Kitsadaniramit and Srisurapanon [9] proposed a transport mode (shuttle bus) for King Mongkut's University of Technology Thonburi Bangkuntien, Thailand (KMUTT) personnel to save on fare costs and travel times by developing a logistic regression model to analyze factors influencing decision-making on the proposed transport mode. The questionnaire survey included factors such as KMUTT personnel socioeconomic characteristics, transport system characteristics, and transport mode satisfaction.

Hector et al. [10] developed a discrete choice model to identify and understand the effects of factors on evacuees' mode choice behavior in Quezon City, the Philippines. The choice models included factors such as evacuation-related decisions factors (departure timing, and destination type), householder and household characteristic factors (age, gender, education, presence of small children, health problem, house ownership, years of residence, and vehicle ownership), a hazard-related factor (source of warning), and mode-related factors (evacuation distance and cost of evacuation).

Sadri et al. [11] investigated the factors that influenced the mode choice decisions for evacuees from Miami Beach, FL, USA who were most likely to use different non-household transportation modes by developing a nested logit model. The model included evacuees' socio-demographics, household characteristics, evacuation destination, and previous experience as input factors and the output factors were transportation mode for evacuee such as special evacuation bus, taxi, regular bus, riding with someone from another household, and another type of mode denoted and aggregated as other.

Murray-Tuite and Wolshon [12], Deka and Carnegie [13], Lindell and Prater [14], and Bian et al. [15] proposed associated factors that may impact on mode split/choice modeling consisting of characteristics of the disaster, distance to safe area, location of evacuees, characteristics of the vehicles, transportation mode (private vehicle or transit), different population groups (tourists or people conducting intermediate trips), level of public transportation service, accessibility to a destination (friend or relative's home, hotel, or shelter), and community density.

Lindell et al. [3] and $\mathrm{Wu}$ et al. [16,17] investigated the factors influencing evacuees' behavior by correlation tests between demographic factors and travel mode use regarding evacuation during a hurricane disaster. The aspects expected to influence the population decision consisted of age, gender, ethnicity, marital status, household size, number of children, education, household income, house ownership, location of evacuees, departure timing, personal experience, source of warning, number of vehicles taken, travel distance, and travel cost. As a result, the location of evacuees, age, gender, ethnicity, marital status, number of children, household size, education, household income, and house ownership were significantly correlated with the use of travel mode.

Lim et al. [18] reviewed the significant criteria associated with decision making for evacuation following a flooding disaster based on the relevant literature. The evacuation decision was the base for building the subsequent models of route and mode choice. The significant criteria included socio-demographic characteristics factors (age, gender, presence of small children, income, car ownership, house ownership, level of education, number of workers in the household, and insurance), capacity-related factors (where capacity indicated the ability of the community to deal with disasters such as disaster knowledge, community competence, and previous flood experience), and risk-related factors (risk analysis, risk information, risk communication, and risk perception). The instance of risk-related factors comprised disaster characteristics, perceived risk, distance to the disaster, possibility of flooding, and source of notice for evacuation.

Yin et al. [19] developed a Poisson regression model to consider the factors contributing to households' choice of the number of vehicles used for evacuation. The related factors fell into two categories: (1) household characteristics (number of vehicle ownership, age, household size, income, education, pet ownership, and travel distance); and (2) evacuation-related characteristics (previous experience, departure timing, destination type, and source of warning). The factors were analyzed in the vehicle usage choice model.

Table 1 presents the factors used in these previous studies based on four categories: (1) social and economic, (2) transport system, (3) vehicle satisfaction, and (4) evacuation-related decisions. The pilot study was conducted based on factors related to decision-making in disaster situations [3,10-19] in order to develop an effective questionnaire for use in the survey. 
Table 1. Factors from previous studies that influence travel mode choice.

\begin{tabular}{|c|c|c|}
\hline & Factor & Author \\
\hline \multirow{13}{*}{ 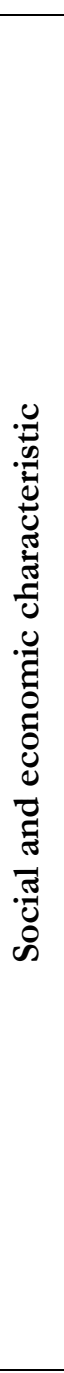 } & Age & $\begin{array}{l}\text { Lindell et al. [3], Wachs [6], Chaiwong and Siridhara [8], Kitsadaniramit } \\
\text { and Srisurapanon [9], Hector R. et al. [10], Sadri et al. [11], Wu et al. } \\
\text { [16],Wu et al. [17], Li et al. [20], Wang and Namgung [21], } \\
\text { Jomnonkwoa et al. [22], Fukuda et al.[23], Wiroj [24]. }\end{array}$ \\
\hline & Sex & $\begin{array}{l}\text { Lindell et al. [3], Wachs [6], Kitsadaniramit and Srisurapanon [9], } \\
\text { Hector R. et al. [10], Sadri et al. [11], Wu et al. [16], Wu et al. [17], Li et } \\
\text { al. [20], Wang and Namgung [21], Jomnonkwoa et al. [22], Fukuda et } \\
\text { al. [23], Danaf et al. [25], Akar et al. [26]. }\end{array}$ \\
\hline & Income & $\begin{array}{l}\text { Lindell et al. [3], Wachs [6], Kitsadaniramit and Srisurapanon [9], Sadri } \\
\text { et al. [11], Bian et al. [15], Wu et al. [16], Wu et al. [17], Wang and } \\
\text { Namgung [21], Jomnonkwoa et al. [22], Fukuda et al. [23], Wiroj [24], } \\
\text { Danaf et al. [25], De Guzman and Diaz [27]. }\end{array}$ \\
\hline & Occupation & $\begin{array}{l}\text { Chaiwong and Siridhara [8], Li et al. [20], Wang and Namgung [21], } \\
\text { Jomnonkwoa et al. [22], Fukuda et al.[23], Wiroj [24]. }\end{array}$ \\
\hline & Education & $\begin{array}{l}\text { Lindell et al. [3], Wachs [6], Hector R. et al. [10], Wu et al. [16], Wu et } \\
\text { al. [17], Wang and Namgung [21], Jomnonkwoa et al. [22], Fukuda et } \\
\text { al. [23], Akar et al. [26]. }\end{array}$ \\
\hline & Frequency & Jomnonkwoa et al. [22] \\
\hline & Vehicle ownership & $\begin{array}{l}\text { Wachs [6], Chaiwong and Siridhara [8], Hector R. et al. [10], Lindell } \\
\text { and Prater [14], Bian et al. [15], Wang and Namgung [21], Jomnonkwoa } \\
\text { et al. [22], Fukuda et al. [23], Wiroj [24], Danaf et al. [25], De Guzman } \\
\text { and Diaz [27]. }\end{array}$ \\
\hline & House ownership & $\begin{array}{l}\text { Lindell et al. [3], Hector R. et al. [10], Sadri et al. [11], Wu et al. [16], } \\
\text { Wu et al. [17]. }\end{array}$ \\
\hline & Marital status & $\begin{array}{l}\text { Lindell et al. [3], Sadri et al. [11], Wu et al. [16], Wu et al. [17], } \\
\text { Jomnonkwoa et al. [22]. }\end{array}$ \\
\hline & Family status & Jomnonkwoa et al. [22] \\
\hline & Household size & $\begin{array}{l}\text { Lindell et al. [3], Bian et al. [15], Wu et al. [16], Wu et al. [17], } \\
\text { Jomnonkwoa et al. [22], Wiroj [24]. }\end{array}$ \\
\hline & Population groups & Murray-Tuite and Wolshon [12]. \\
\hline & Trip purposes & Wang and Namgung [21], Fukuda et al. [23]. \\
\hline \multirow{5}{*}{ 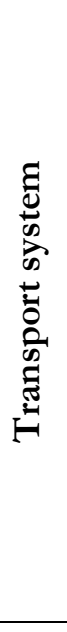 } & Fare cost & $\begin{array}{l}\text { Lindell et al. [3], Wachs [6], Kitsadaniramit and Srisurapanon [9], } \\
\text { Hector R. et al. [10], Wu et al. [16], Wu et al. [17], Jomnonkwoa et al. } \\
\text { [22], Fukuda et al. [23], Wiroj [24], Danaf et al. [25], Akar et al. [26], } \\
\text { Sutipan and Lueatep [28], Tangphaisankun et.al [29]. }\end{array}$ \\
\hline & Travel time & $\begin{array}{l}\text { Wachs [6], Chaiwong and Siridhara [8], Kitsadaniramit and } \\
\text { Srisurapanon [9], Li et al. [20], Fukuda et al. [23], Wiroj [24], Danaf et } \\
\text { al. [25], Akar et al. [26], De Guzman and Diaz [27], Sutipan and } \\
\text { Lueatep [28], Tangphaisankun et al. [29]. }\end{array}$ \\
\hline & Distance & $\begin{array}{l}\text { Lindell et al. [3], Chaiwong and Siridhara [8], Hector R. et al. [10], } \\
\text { Murray-Tuite and Wolshon [12], Wu et al. [16], Wu et al. [17], } \\
\text { Jomnonkwoa et al. [22]. }\end{array}$ \\
\hline & $\begin{array}{l}\text { Characteristics of the } \\
\text { vehicles }\end{array}$ & Lindell and Prater [14]. \\
\hline & Number of trips & Li et al. [20], Wiroj [24]. \\
\hline \multirow{2}{*}{ 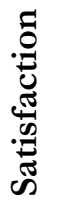 } & Convenience & $\begin{array}{l}\text { Wachs [6], Kitsadaniramit and Srisurapanon [9], De Guzman and Diaz } \\
\text { [27], Tangphaisankun et al. [29]. }\end{array}$ \\
\hline & Safety & $\begin{array}{l}\text { Wachs [6], Kitsadaniramit and Srisurapanon [9], Murray-Tuite and } \\
\text { Wolshon [12], Akar et al. [26], Tangphaisankun et al. [29]. }\end{array}$ \\
\hline
\end{tabular}


Table 1. Factors from previous studies that influence travel mode choice. (continued).

\begin{tabular}{|c|c|c|}
\hline \multicolumn{2}{|r|}{ Factor } & Author \\
\hline \multirow{8}{*}{ 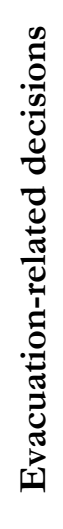 } & $\begin{array}{l}\text { Characteristics of the } \\
\text { disaster }\end{array}$ & Hector R. et al. [10], Murray-Tuite and Wolshon [12]. \\
\hline & Departure timing & Lindell et al. [3], Hector R. et al. [10], Wu et al. [16], Wu et al. [17]. \\
\hline & Destination type & Hector R. et al. [10], Sadri et al. [11]. \\
\hline & Source of warning & Lindell et al. [3], Hector R. et al. [10], Wu et al. [16], Wu et al. [17]. \\
\hline & Location of evacuees & $\begin{array}{l}\text { Lindell et al. [3], Murray-Tuite and Wolshon [12], Wu et al. [16], Wu et } \\
\text { al. [17]. }\end{array}$ \\
\hline & Transportation mode & Deka and Carnegie [13]. \\
\hline & Previous experience & Lindell et al. [3], Sadri et al. [11], Wu et al. [16], Wu et al. [17]. \\
\hline & $\begin{array}{l}\text { Accessibility to a } \\
\text { destination }\end{array}$ & Bian et al. [15]. \\
\hline
\end{tabular}

\section{Utility Function and Logistic Regression Model}

A utility function was used to define the individual preferences for each travel mode. The value of the utility is typically used to compare the different modes of travel. A mode with a higher utility value is more likely to be chosen [30]. Equation (1) was used to quantify the utility based on two terms: (1) the deterministic component and (2) the random component. First, the deterministic component $\left(\mathrm{V}_{\text {in }}\right)$ represents a set of individuals capable of providing all the required information for each travel mode, and their preferred travel mode. Second, the random component $(\varepsilon)$ indicates the uncertainty in making a decision. Equation (2) shows the associated parameters and factors to calculate $V_{\text {in }}$.

$$
\begin{gathered}
U_{i n}=V_{i n}+\varepsilon \\
V_{i n}=\beta_{0}+\beta_{1} x_{1}+\beta_{2} x_{2}+\ldots+\beta_{n} x_{n}
\end{gathered}
$$

where $\mathrm{U}_{\text {in }}$ is the utility of person $\mathrm{n}$ choosing travel mode $\mathrm{i} ; \mathrm{V}_{\text {in }}$ is the deterministic component of utility; $\varepsilon$ is the random component of utility; $\beta_{0}$ is the model constant; and $\beta_{1}, \ldots, \beta_{\mathrm{n}}$ are the parameters corresponding to the explanatory factors $\left(\mathrm{x}_{1}, \ldots, \mathrm{x}_{\mathrm{n}}\right.$ the set of independent factors) [31]. These parameters were estimated using logistic regression analysis $[5,23,27]$ as explained in the next paragraphs.

The logistic regression model was analyzed to represent the relationship between an individual's decision and the various factors that affect the selection of travel mode choices. The dependent variable was the population proportion or probability $(\mathrm{P})$ that the resulting outcome indicates the presence of a condition usually denoted using a binary indicator variable coded as 1 or 0 . The model was then analyzed under the assumption that a set of individuals selected the highest utility to their preference.

$$
\begin{gathered}
P n(i)=\frac{e^{U i n}}{e^{U i n}+e^{U j n}} \\
P n(i)=\frac{1}{1+e^{-(U i n+U j n)}}
\end{gathered}
$$

Equations (3) and (4) were used to estimate the probability of decision-making, where $U$ is the utility function of each travel mode and the unknown parameters $\beta_{1}, \ldots, \beta_{n}$ in Eq. (2) are estimated using maximum likelihood methods [31]. 


\section{Research Methodology}

The methodology consisted of two subsections: 1) questionnaire design, involving the process of issuing the questionnaire and data collection and 2) modeling methodology, explaining the procedure, and the division into cases.

\subsection{Questionnaire Design}

First, a pilot survey was conducted to identify the key information in order to construct an effective questionnaire. The authors focused on those parties with the responsibility to take action regarding disaster prevention to understand their perspectives toward the study area: characteristics, personal attitudes and behavior, government and villager procedural guidelines during disasters, previous flooding and landslide disasters, and emergency response capability.

The head of prevention and operations disaster in Uttaradit province, village disaster surveillance networks, village headman, and the villagers who were expected to suffer were defined as the potential target group in this research. The questionnaire was developed according to the key information obtained from the pilot survey. The questionnaire in this research collected data in 4 parts: 1) social and economic characteristics 2) disaster relative information 3) satisfaction with travel mode choice and 4) the selection of travel modes between government vehicles and private vehicles from assuming nine situations classified into four categories for model analysis (social and economic characteristic factors, disaster relative factors, vehicle satisfaction factors, and transport system factors).

Social and economic characteristic factors - sex, age, family status, household size, families with young members, families with elderly members, education, occupation, income, and car ownership.

Disaster relative factors - experienced a disaster, experience of evacuating to shelter, preparedness to evacuate, and recognition of shelter location.

Vehicle satisfaction factors - safety of evacuees while evacuating, reaching the destination quickly, convenience of vehicle access, traveling costs, crowding on vehicle, proportional family management for evacuation (e.g. management of people in the same family evacuating together), ease of the evacuation procedures of mode, and evacuation at night

Transport system factors - difference between travel time of government vehicles and private vehicles, walking time to the assembly point, and difference between the number of passenger seats in government vehicles compared to private vehicles.

The assumed attitudinal questions regarding the transport system factor were designed using a stated preference (SP) survey method $[8,9,23]$ which assumes alternative situations with different values of factors. The method used three factors as shown in Table 2: (1) the difference in travel time between a private vehicle and a government vehicle, (2) walking time to the assembly point, and (3) the different passenger seat capacity between private and government vehicles. These three factors were calculated according to the primary data in the study area. First, the different travel times were calculated using the route network, vehicle speed, and duration time to prepare for evacuation. Second, the walking time was obtained considering the location of the assembly point and waking speed. Third, the differences in capacity were considered based on vehicle size and the required space for each passenger. Each of these factors was considered based on three levels sorted in ascending order, where level 1 represented the lowest different value, level 2 represented the middle different value, and level 3 represented the highest different value. These three factors were used to generate the possible scenarios.

The possible scenarios were generated using an experimental design. Each scenario considered the three aforementioned factors where for each factor the appropriate level was determined using Taguchi factorial theory $[8,28]$. As shown in Fig. 1, the first scenario was generated, consisting of level 1 of the different travel times, level 1 of walking time to assembly point, and level 1 of the different passenger seats (Fig. 1-A). These levels were transformed to the checklist choice according to two alternative choices (private vehicle and government vehicle) to conduct the survey. The explanation of how to transform the level of each involved factor is provided in Fig. 1-B. As shown in Table 3, the checklists for each scenario were summarized as the key checklists for the respondent interviews. 
Table 2. Different values of factors in each level.

\begin{tabular}{lccc}
\hline \multicolumn{1}{c}{ Factor } & \multicolumn{3}{c}{ Level } \\
\cline { 2 - 4 } & $\mathbf{1}$ & $\mathbf{2}$ & $\mathbf{3}$ \\
\hline Factor 1 Difference between travel times (minutes) & 5 & 8 & 11 \\
Factor 2 Walking time to the assembly point (minutes) & 10 & 15 & 20 \\
Factor 3 Difference between passenger seats (seats) & 10 & 15 & 20 \\
\hline
\end{tabular}

A. Taguchi Factorial design of 3 factors with 3 levels

\begin{tabular}{|c|c|c|c|}
\hline \multicolumn{4}{|c|}{ Level of factor in each situation } \\
\hline Situation & Factor $\mathbf{1}$ & Factor $\mathbf{2}$ & Factor 3 \\
\hline $\mathbf{1}$ & 1 & 1 & 1 \\
\hline $\mathbf{2}$ & 1 & 2 & 2 \\
\hline $\mathbf{3}$ & 1 & 3 & 3 \\
\hline $\mathbf{4}$ & 2 & 1 & 2 \\
\hline $\mathbf{5}$ & 2 & 2 & 3 \\
\hline $\mathbf{6}$ & 2 & 3 & 1 \\
\hline $\mathbf{7}$ & 3 & 1 & 3 \\
\hline $\mathbf{8}$ & 3 & 2 & 1 \\
\hline $\mathbf{9}$ & 3 & 3 & 2 \\
\hline
\end{tabular}

\begin{tabular}{|c|c|c|c|}
\hline \multicolumn{4}{|c|}{ Value of level of factor in each situation } \\
\hline Situation & Factor $\mathbf{1}$ & Factor $\mathbf{2}$ & Factor $\mathbf{3}$ \\
\hline 1 & 5 & 10 & 10 \\
\hline 2 & 5 & 15 & 15 \\
\hline 3 & 5 & 20 & 20 \\
\hline 4 & 8 & 10 & 15 \\
\hline 5 & 8 & 15 & 20 \\
\hline 6 & 8 & 20 & 10 \\
\hline 7 & 11 & 10 & 20 \\
\hline 8 & 11 & 15 & 10 \\
\hline 9 & 11 & 20 & 15 \\
\hline
\end{tabular}

B. Example of situation 1 presented to respondents for them to indicate their decision

\begin{tabular}{|c|c|c|c|c|}
\hline Situation 1 & Travel time & Walking time & Passenger seats & Choose \\
\hline Government vehicle & $15 \mathrm{~min}$. & $10 \mathrm{~min}$. & 12 seats & $\square$ \\
\hline Private vehicle & $10 \mathrm{~min}$. & - & 2 seats & $\square$ \\
\hline
\end{tabular}

Example of how to calculate value of each factor in situation 1;

Step 1: assign values for travel time, walking time, and passenger seats for private vehicle of 10,0 , and 2, respectively.

Step 2: calculate values of travel time, walking time, and passenger seats for government vehicle using the different values of factors in situation 1 such as travel time of government vehicle $=($ different travel time $)+($ private vehicle's travel time $)=5+$ $10=15$ minutes. Then, walking time $=10+0=10$ minutes and passenger seats $=10+2=12$ seats.

Fig 1. Experimental design for transport system factor.

Table 3. Assumed attitudinal situations.

\begin{tabular}{ccc|ccc}
\hline \multirow{2}{*}{ Situation } & \multicolumn{2}{c|}{ Private vehicle } & \multicolumn{3}{c}{ Government vehicle } \\
\cline { 2 - 6 } & $\begin{array}{c}\text { Travel time } \\
\text { (minutes) }\end{array}$ & $\begin{array}{c}\text { Passenger seats } \\
\text { (seats) }\end{array}$ & $\begin{array}{c}\text { Travel time } \\
\text { (minutes) }\end{array}$ & $\begin{array}{c}\text { Walking time } \\
\text { (minutes) }\end{array}$ & $\begin{array}{c}\text { Passenger seats } \\
\text { (seats) }\end{array}$ \\
\hline 1 & 10 & 2 & 15 & 10 & 12 \\
2 & 15 & 2 & 20 & 15 & 17 \\
3 & 20 & 2 & 25 & 20 & 22 \\
4 & 7 & 5 & 15 & 10 & 20 \\
5 & 12 & 5 & 20 & 15 & 25 \\
6 & 17 & 5 & 25 & 20 & 15 \\
7 & 4 & 10 & 15 & 10 & 30 \\
8 & 9 & 10 & 20 & 15 & 20 \\
9 & 14 & 10 & 25 & 20 & 15 \\
\hline
\end{tabular}


The data used in this study were drawn from a field survey in the Mae Pong watershed, Laplae district, Uttaradit province, Thailand. Respondents were a sample group of people living in this area including the village headman, community leaders, disaster surveillance network, and people of all occupations who were randomly selected based on a stratified sampling approach of households for use as representatives of the inhabitants in the study area. The following statement demonstrates whether the survey was conducted according to the decision rule of discrete choice theory. Either heads of the family or the household representatives that were fully able to decide for their families were defined as the potential respondents. Only face-to-face interviews were conducted in order to observe the reaction of each household representative.

In total, 219 samples were gathered from the study area from which inappropriate samples not included in the mode choice model development were eliminated such as incomplete obtained data, samples without car ownership, respondents with hesitant decisions, and respondents who decided not to evacuate. As a result, 80 inappropriate samples were eliminated leaving 139 samples to develop the travel mode choice model between government vehicles and private vehicles.

\subsection{Modeling Methodology}

An accurate and appropriate process was required to develop the two alternative travel mode choices in the model to predict the travel mode selection with statistical significance.

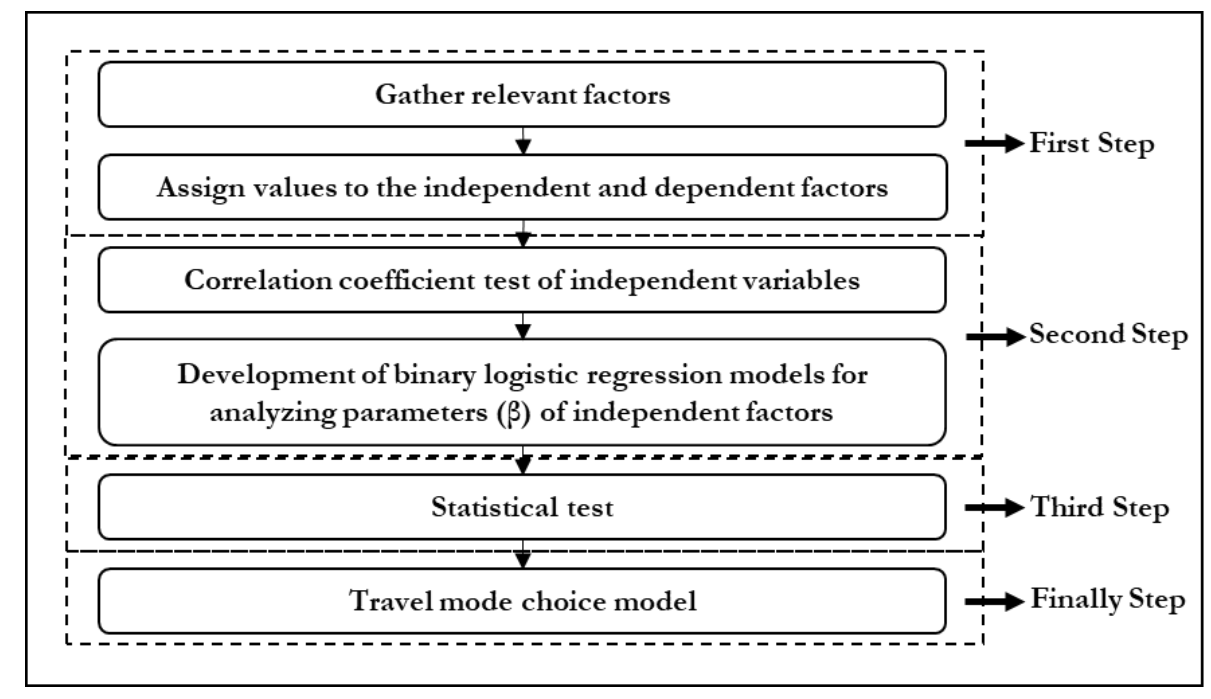

Fig. 2. Modeling process.

Figure 2 presents the three main steps to develop the mode choice model. First, the probability of selecting travel mode between private vehicle and government vehicle was defined as the dependent variable. The mode choice model was considered based on three cases, in which each case was regarded using the different independent variables as:

Model 1 consisted of social and economic characteristic factors, disaster relative factors, and vehicle satisfaction factors in the analysis.

Model 2 consisted of transport system factors in the analysis.

Model 3 consisted of all factors in the study in the analysis.

Second, Spearman's correlation test was used to determine if the correlation coefficients of all the independent variables selected in each model were not higher than 0.5 in order to avoid multicollinearity. Then, the parameters of the independent variables were estimated using binary logistic regression. This technique is well suited for our purposes because we were concerned with a dichotomous final outcome (use government vehicles or use private vehicles). The independent variables that could best predict the outcome were selected for use in the model using the stepwise selection technique.

Third, three major tests were performed to obtain an appropriate model involving: (1) model chi-square, (2) the Wald statistic, and (3) pseudo $\mathrm{R}^{2}$. The model chi-square value was used to verify the appropriateness of each developed equation. The Wald statistic was determined to consider whether each independent 
variable was significant in predicting the outcome. The pseudo $\mathrm{R}^{2}$ was used to test that the $\mathrm{R}^{2}$ of the models was 0.20 or higher. Finally, factors that were statistically significant were kept in the travel mode choice model. Statistical significance was set at the $95 \%$ confidence level.

\section{Research Results}

The results of the study are presented to describe the social and economic characteristics of the sample together with their attitude towards the transportation system (section 5.1). The results of the three models consisted of different independent factors, according to the main objective. This section discusses the factors that influenced the travel mode choice based on the three models. The results are presented separately for each model in sections 5.2 and 5.3.

\subsection{Demographic and Socioeconomic Profile}

Table 4 presents the descriptive statistics of the demographic and socioeconomic profile. The main characteristics of the respondents were summarized in nine dimensions: (1) sex, 46 percent of respondents were male; (2) age, mainly 51-70 years; (3) education, mainly completed primary school; (4) occupation, agriculture (orchardists); (5) family status, mostly householders; (6) household size, 3-4 members per household; (7) young and elderly members, 48.2 percent young and 28.8 percent elderly; (8) average income per household, USD 572.82 per month; and (9) number of vehicles per family, approximately 1-2 cars.

Table 4. Descriptive statistics of demographic and socioeconomic profile of respondents.

\begin{tabular}{llc}
\hline Factor & Level & Percentage \\
\hline Sex & Male & 46.00 \\
& Female & 54.00 \\
\hline Age & $<30$ years & 3.00 \\
& $30-50$ years & 39.00 \\
& $51-70$ years & 54.00 \\
& $>70$ years & 4.00 \\
\hline Education & Primary school & 58.30 \\
& Secondary school & 22.30 \\
& Upper secondary school & 12.90 \\
& Undergraduate or higher & 6.50 \\
\hline Occupation & Agriculture & 83.50 \\
& Government official or state enterprise employee & 5.00 \\
& Employee & 5.00 \\
& Owner & 2.20 \\
& Others & 4.30 \\
\hline Family status & Householder & 68.30 \\
& Resident & 31.70 \\
\hline Household size & $1-2$ members & 15.10 \\
& $3-4$ members & 55.40 \\
& $5-6$ members & 28.10 \\
& $>6$ members & 1.40 \\
\hline Families with young members & Yes & 48.20 \\
& No & 51.80 \\
\hline Families with elderly members & Yes & 28.80 \\
& No & 71.20 \\
\hline Income (USD/month) & $<319$ & 21.60 \\
& $319-637$ & 48.20 \\
& $638-958$ & 25.20 \\
& $>958$ & 5.00 \\
\hline Car ownership & 1 car & 81.58 \\
& $\geq 2$ cars & 19.42 \\
\hline
\end{tabular}


Then, each respondent was interviewed to obtain their personal experience on disasters. Table 5 provides the results using four dimensions: (1) experienced a disaster, (2) experience of evacuating to shelter, (3) preparedness to evacuate if a disaster occurred, and (4) recognition of shelter location.

Table 5. Descriptive statistics of disaster-related factors.

\begin{tabular}{lcc}
\hline Factor & Response & Percentage \\
\hline Experienced a disaster & Yes & 67.00 \\
(Have you ever experienced a disaster?) & No & 33.00 \\
\hline Experience of evacuating to shelter & Yes & 55.00 \\
(Have you ever evacuated to a shelter?) & No & 45.00 \\
\hline Preparedness to evacuate if disaster occurred & Yes & 90.00 \\
(Are you ready to evacuate immediately if a disaster occurs again?) & No & 10.00 \\
\hline Recognition of shelter location & Yes & 86.00 \\
(Do you know where the location of the shelter is?) & No & 14.00 \\
\hline
\end{tabular}

The attitude of the respondents regarding the selection of vehicles for evacuation mainly focused on safety of evacuees while evacuating $(41.33 \%)$, followed by reaching the destination quickly $(25.56 \%)$, and convenience of vehicle access $(22.00 \%)$, respectively, (Table 6).

Table 6. Factors influencing respondent selection of vehicle.

\begin{tabular}{lcc}
\hline Factor & Percentage & Rank \\
\hline Safety of evacuees while evacuating & 41.33 & 1 \\
Reaching the destination quickly & 25.56 & 2 \\
Convenience of vehicle access & 22.00 & 3 \\
Traveling costs & 1.56 & 6 \\
Crowding in vehicle & 1.33 & 7 \\
Proportional family management for evacuation & 1.78 & 5 \\
No choice & 6.44 & 4 \\
\hline
\end{tabular}

A pickup car was assigned as the choice for the private vehicle mode in the model due to the major occupation and physical geography of the evacuation area, as all household representatives indicated their families had at least one pickup car per household. Based on technical reports on the study area [1,2], the authors identified that evacuees had 2 choices of transportation mode for reaching the shelter: (1) government vehicle standing by at the assembly point after the disaster alarm had been activated and (2) private pick up car.

\subsection{Mode Choice Model Analysis using Binary Logistic Regression}

The travel mode choice models were analyzed using binary logistic regression [8,9,20]. A value of 1 was assigned when the probability of selecting a travel mode was government vehicles and 0 for traveling by private vehicles. Parameters of factors that were appropriate and statistically significant in each model are shown in Tables 7, 8, and 9. All the independent factors of each model were tested using correlation to focus on the multicollinearity problem. The coefficients for each pair of independent factors were not higher than 0.5 , which indicated these independent factors did not have any multicollinearity problem. Then stepwise selection was employed in order to select the appropriate factors for the model based on their statistical performance to predict the outcome by regarding the -2LL (-2likelihood ratio) of each independent factor. Factors that were not statistically significant were excluded from the model.

Model 1 analysis considered social and economic characteristic factors (sex, age, family status, household size, families with young members, families with elderly members, education, occupation, income, and car ownership), disaster relative factors (experienced a disaster, experience of evacuating to shelter, preparedness to evacuate, and recognition of shelter location), and vehicle satisfaction factors (safe, fast, comfortable, cheap cost, crowding, privacy, ease of use, and evacuation at night). Seven factors were selected 
for the model according to their performance, as these seven factors were significant in explaining the outcome as shown in Table 7.

Table 7. Model 1 estimation results for travel mode choice decisions.

\begin{tabular}{|c|c|c|c|c|}
\hline Factor & $\beta$ & S.E. & Wald & Sig. \\
\hline $\begin{array}{l}\text { Sex } \\
\quad \text { (respondent's gender: } 0=\text { female, } 1=\text { male) }\end{array}$ & -1.644 & 0.490 & 11.239 & 0.001 \\
\hline $\begin{array}{l}\text { Children } \\
\text { (families with young member: } 0=\text { no, } 1=\text { yes) }\end{array}$ & -1.335 & 0.489 & 7.467 & 0.006 \\
\hline $\begin{array}{l}\text { No.Car } \\
\text { (car ownership: } 0=1 \text { vehicle, } 1=\text { higher than or equal to } 2 \\
\text { vehicle) }\end{array}$ & -1.245 & 0.614 & 4.110 & 0.043 \\
\hline $\begin{array}{l}\text { Ever.Disaster } \\
\quad(\text { experienced a disaster: } 0=\text { never, } 1=\text { ever })\end{array}$ & -1.386 & 0.560 & 6.130 & 0.013 \\
\hline $\begin{array}{l}\text { Know.Shelter } \\
\quad(\text { recognition of shelter location: } 0=\text { no, } 1=\text { yes })\end{array}$ & -2.346 & 0.935 & 6.292 & 0.012 \\
\hline $\begin{array}{l}\text { Safety* } \\
\text { (safety of evacuees while evacuating) }\end{array}$ & 1.531 & 0.479 & 10.212 & 0.001 \\
\hline $\begin{array}{l}\text { Comfort* } \\
\text { (convenience of vehicle access) }\end{array}$ & 1.023 & 0.290 & 12.448 & 0.000 \\
\hline Constant & 4.205 & 1.122 & 14.038 & 0.000 \\
\hline
\end{tabular}

\section{Model 1 Statistics}

Likelihood ratio chi-square (LR $\chi 2)$

Degrees of freedom

Prob $>\mathrm{Chi}^{2}(\chi 2)$

-2 Log likelihood

Pseudo R2

0.405

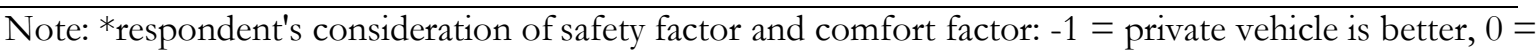
both equal (satisfaction is the same), and $1=$ government vehicle is better

Model 2 analysis comprised transport system factors (difference between travel time of government vehicles and private vehicles, walking time to the assembly point, and the difference between the number of passenger seats in government vehicles and private vehicles). Table 8 presents the two factors that had a significant impact on the outcome.

Table 8. Model 2 estimation results for travel mode choice decisions.

\begin{tabular}{|c|c|c|c|c|}
\hline Factor & $\beta$ & S.E. & Wald & Sig. \\
\hline $\begin{array}{l}\text { Travel_time } \\
\text { (difference between travel time of government vehicles and } \\
\text { private vehicles (minutes)) }\end{array}$ & -0.418 & 0.030 & 196.798 & 0.000 \\
\hline $\begin{array}{l}\text { Walk_tBus } \\
\text { (walking time to the assembly point (minutes)) }\end{array}$ & -0.211 & 0.018 & 144.053 & 0.000 \\
\hline Constant & 6.479 & 0.413 & 246.333 & 0.000 \\
\hline Model 2 Statistics & & & & \\
\hline Likelihood ratio chi-square (LR $\left.\chi^{2}\right)$ & \multicolumn{4}{|c|}{377.804} \\
\hline Degrees of freedom & \multicolumn{4}{|c|}{2} \\
\hline Prob $>\operatorname{Chi}^{2}(\chi 2)$ & \multicolumn{4}{|c|}{0.000} \\
\hline -2 Log likelihood & \multicolumn{4}{|c|}{$1,356.354$} \\
\hline Pseudo $\mathrm{R}^{2}$ & \multicolumn{4}{|c|}{0.261} \\
\hline
\end{tabular}


Model 3 analysis comprised social and economic characteristic factors (sex, age, family status, household size, families with young members, families with elderly members, education, occupation, income, and car ownership), disaster relative factors (experienced a disaster, experience of evacuating to shelter, preparedness to evacuate, and recognition of shelter location), vehicle satisfaction factors (safe, fast, comfortable, cheap cost, crowding, privacy, ease of use, and evacuation at night), and transport system factors (difference between travel time of government vehicles and private vehicles, walking time to the assembly point, and difference between the number of passenger seats in government vehicles and private vehicles).

Table 9 presents the eight factors that were selected that were the most important in predicting the outcome.

Table 9. Model 3 estimation results for travel mode choice decisions.

\begin{tabular}{|c|c|c|c|c|}
\hline Factor & $\beta$ & S.E. & Wald & Sig. \\
\hline $\begin{array}{l}\text { Sex } \\
\text { (respondent's gender: } 0=\text { female, } 1=\text { male) }\end{array}$ & -0.444 & 0.145 & 9.337 & 0.002 \\
\hline $\begin{array}{l}\text { Household size } \\
\text { (household size: } 0=\text { households with between } 1 \text { and } 4 \\
\text { members, } 1=\text { households with more than } 4 \text { members) }\end{array}$ & 0.766 & 0.158 & 23.481 & 0.000 \\
\hline $\begin{array}{l}\text { Education } \\
\text { (respondent's education level: } 0=\text { lower than secondary level, } \\
1=\text { higher than or equal to secondary level) }\end{array}$ & -0.544 & 0.149 & 13.296 & 0.000 \\
\hline $\begin{array}{l}\text { Fast* } \\
\text { (reaching the destination quickly) }\end{array}$ & 0.407 & 0.083 & 24.110 & 0.000 \\
\hline $\begin{array}{l}\text { Privacy* } \\
\text { (proportional family management for evacuation) }\end{array}$ & 0.474 & 0.152 & 9.665 & 0.002 \\
\hline $\begin{array}{l}\text { Easy* } \\
\text { (ease of the evacuation procedures of mode) }\end{array}$ & 0.163 & 0.083 & 3.858 & 0.049 \\
\hline $\begin{array}{l}\text { Travel_time } \\
\text { (difference between travel time of government vehicles and } \\
\text { private vehicles (minutes)) }\end{array}$ & -0.464 & 0.032 & 205.383 & 0.000 \\
\hline $\begin{array}{l}\text { Walk_tBus } \\
\text { (walking time to the assembly point (minutes)) }\end{array}$ & -0.167 & 0.013 & 152.752 & 0.000 \\
\hline Constant & 6.818 & 0.427 & 254.538 & 0.000 \\
\hline Model 3 Statistics & & & & \\
\hline Likelihood ratio chi-square (LR $\left.\chi^{2}\right)$ & \multicolumn{4}{|c|}{491.343} \\
\hline Degrees of freedom & \multicolumn{4}{|c|}{8} \\
\hline Prob > $\mathrm{Chi}^{2}(\chi 2)$ & \multicolumn{4}{|c|}{0.000} \\
\hline -2 Log likelihood & \multicolumn{4}{|c|}{$1,242.724$} \\
\hline Pseudo $\mathrm{R}^{2}$ & \multicolumn{4}{|c|}{0.325} \\
\hline
\end{tabular}

Note: *respondent's consideration of fast factor, privacy factor and easy factor: $-1=$ private vehicle is better, $0=$ both equal (satisfaction is the same), and $1=$ government vehicle is better.

The goodness of fit test of each model (pseudo R 2 ) using the Cox \& Snell R statistic was used to find the percentage variation explained in the logistic regression analysis. From Tables 7-9, all three models had pseudo $\mathrm{R}^{2}$ values greater than 0.20 , indicating that the models were all acceptable. Independent factors in the equation could explain $0.405,0.261$, and 0.325 for the selection of travel modes in models 1,2 , and 3 , respectively.

All coefficients in the logistic regression equation were tested using chi-square values by assuming $\mathrm{H}_{0}$ : $\beta_{1}, \ldots, \beta_{n}=0$ and $H_{1}: \beta_{1}, \ldots, \beta_{n} \neq 0$. In Tables 7-9, significant values of 0.00 indicate that the results in all three models suggest rejecting $\mathrm{H}_{0}$ and accepting $\mathrm{H}_{1}$, indicating that the coefficient of each model affected at least one independent factor. Models 1, 2, and 3 were able to accurately predict the probability of selecting travel modes for evacuation with averages of $78.40,73.46$, and 75.30 percent, respectively. 


\subsection{Factor Direction Analysis}

Model 1 contained seven factors that were significant and appropriate and its utility function is shown in Eq. (5):

$$
\begin{aligned}
& U_{(\text {Public })}=4.205-1.644(\text { Sex })-1.335(\text { Children })-1.245(\text { No.Car })-1.386(\text { Ever.Disaster }) \\
& -2.346(\text { Know.Shelter })+1.531(\text { Safety })+1.023(\text { Comfort })
\end{aligned}
$$

Notation:

$$
\text { Sex } \quad \text { sex factor: } 0=\text { female, } 1=\text { male }
$$

Children families with young member factor: $0=$ no, $1=$ yes

No.Car car ownership factor: $0=1$ vehicle, $1=$ higher than or equal to 2 vehicle

Ever.Disaster experienced a disaster factor: $0=$ never, $1=$ ever

Know.Shelter recognition of shelter location factor: $0=$ no, $1=$ yes

Safety, Comfort safety of evacuees while evacuating factor, convenience of vehicle access factor: $-1=$ private vehicle is better, $0=$ both equal (satisfaction is the same), and 1 = government vehicle is better

The sign in front of parameters of independent factors indicates the trend of satisfaction in travel mode choice. Equation (5) for Model 1 showed that males were less satisfied with the choice of evacuation by government vehicles than females. Families with children having more than one private vehicle had decreased satisfaction with the choice of government vehicles. In addition, evacuees who had experienced a disaster or recognized the location of the shelter were less satisfied with evacuation by government vehicles. On the other hand, if the evacuees considered comfort or safety, then government vehicles were better than private vehicles, reinforcing the decision to prefer travelling in a government vehicle.

Model 2 contained two factors that were significant and appropriate and its utility function is presented in Eq. (6):

$$
U_{(\text {Public })}=6.479-0.418(\text { Travel_time })-0.211(\text { Walk_tBus })
$$

Notation:

Travel_time_difference between travel time of government vehicles and private vehicles (minutes)

Walk_tBus walking time to the assembly point (minutes)

The results of Model 2 showed that if the travel time by government vehicles was longer than by private vehicles, the probability of travel mode choice by government vehicles decreased. In the same way, if the time to walk to the assembly point for using government vehicles increased, the probability of travel mode choice of government vehicles decreased. Eq. (7):

Model 3 contained eight factors that were significant and appropriate and its utility function is shown in

$$
\begin{aligned}
& U_{(\text {Public })}=6.818-0.444(\text { Sex })+0.766(\text { Householdssize })-0.544(\text { Education })+0.407(\text { Fast }) \\
& +0.474(\text { privacy })+0.163(\text { Easy })-0.464(\text { Travel_time })-0.167(\text { Walk_tBus })
\end{aligned}
$$

Notation:

Sex

Household size

Education sex factor: $0=$ female, $1=$ male

household size factor: $0=$ households with between 1 and 4 members, $1=$ households with greater than 4 members

education level factor: $0=$ lower than secondary level, $1=$ higher than or equal to secondary level 


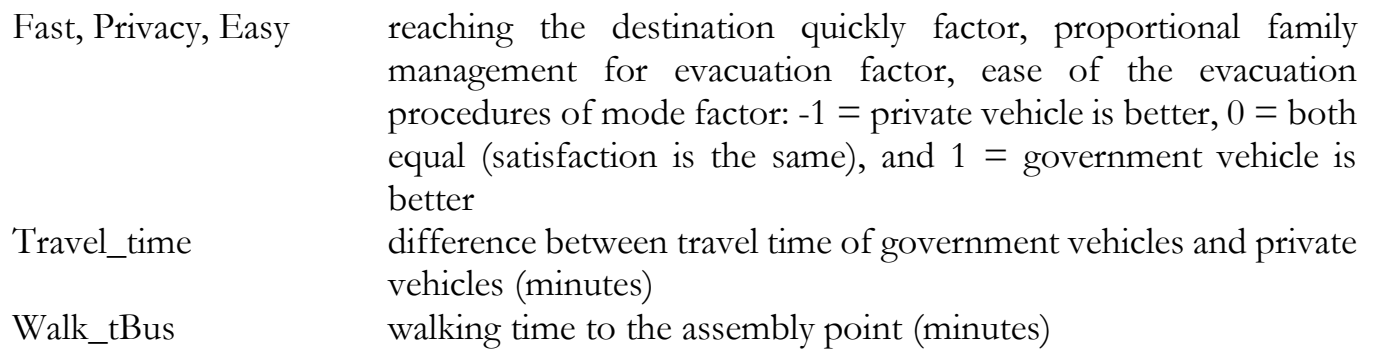

Equation (7) showed that males were less satisfied with the choice of evacuation by government vehicles than females, as was the case for Model 1. Household representatives with either less than five members in their family or with higher education levels than the primary level were more likely to select private vehicle mode. In terms of the vehicle satisfaction factors, if the government vehicles for evacuation were faster, had more privacy or were easier to use than private vehicles, then respondents would select the government vehicle mode. However, if the travel time in a government vehicle or the time to walk to the assembly point increased, then selection of the government vehicle mode decreased.

\subsection{Discussion}

The inter-correlation test was conducted to focus on the relationship between each independent factor and the selection of travel mode choices regarding the correlation coefficient $(r)$ with statistical significance tested at either the $95 \%$ or $99 \%$ confidence level. The analysis indicated the independent factors significantly correlated with the selection of travel mode choice were: 1) families with a young member $(r=-0.178)$, education level $(r=-0.214)$, car ownership $(r=-0.203)$, and preparedness to evacuate $(r=0.170)$ were significant at the 0.01 level; 2$) \operatorname{sex}(r=-0.247)$, experienced a disaster $(r=-0.251)$, recognition of shelter location $(r=-0.242)$, safety of evacuees while evacuating $(r=0.377)$, reaching the destination quickly $(r=$ 0.354), convenience of vehicle access $(r=0.408)$, proportional family management for evacuation $(r=0.103)$, ease of the evacuation procedures of mode $(r=0.316)$, difference travel time $(r=-0.401)$, and walking time to the assembly point $(r=-0.327)$ were significant at the 0.05 level. These independent factors had low to medium level inter-correlation with the selection of travel mode choices $(0.170 \leq r \leq 0.408)$.

The factors can be discussed using four dimensions: (1) social and economic characteristic factors, (2) disaster relative factors, (3) vehicle satisfaction factors, and (4) transport system factors.

\section{1) Social and economic characteristic factors}

Sex: Females tended to prefer using the government vehicle more than males $(\beta=-1.644$ in model 1 and $\beta=-0.444$ in model 3), while males were more likely to evacuate by private vehicle. According to the survey, the authors perceived from the face-to-face interviews that females were more likely to be concerned about their safety. The literature mentioned that females well better prepared and very active [34], which was consistent with the current results where the correlation test between sex and preparedness to evacuate $(r=$ -0.170) revealed that if a disaster occurs, females were better prepared to evacuate than males. From this it can be concluded that those that were well prepared probably wanted to evacuate by government vehicle. In addition, gender was positively correlated with the education level $(r=0.214)$ which could be interpreted as indicating that the heads of family with lower than secondary education level were more likely to prefer using a government vehicle according to the analysis of the education factor in model 3.

Household size: Families with more than five members were more likely to select a government vehicle ( $\beta=0.766$ in model 3$)$, with the major reason being that they wanted to move their whole family as a single group. Previous study also reported that large-sized families commonly needed many vehicles for evacuation [35]. This implies that a government vehicle may be the more suitable alternative in such cases.

Families with young member factor: Families with young members under ten years old tended to use a private vehicle ( $\beta=-1.335$ in model 1$)$ due to their concern about the safety of the young member, as using the government vehicle commonly requires the evacuees to walk to the supporting vehicle. The literature mentioned that the families with young members are more like to select their own vehicle compared to the families without young members [10]. 
Education level: The heads of families with higher than secondary level education were more likely to use a private vehicle for evacuation due to the issue of walking time to government vehicles $(\beta=-0.544$ in model 3). [10] mentioned that the heads of families with high education were more likely to use their own vehicles. In addition, the education level was positively correlated with car ownership $(r=0.211)$, indicating that households with more than one private vehicle were more likely to evacuate using a private vehicle. Moreover, the education level was negatively correlated with the safety of evacuees while evacuating $(r=$ 0.202), indicating that safety positively affected the outcome of model 3 . Thus, it can be concluded that car ownership and safety while evacuating were reflected in the results related to model 1.

Car ownership: Based on the analytical result in model $1(\beta=-1.245)$, the families with at least two car ownerships were more likely to prefer using their own pick up car, as this type of vehicles was easily accessible compared to the government vehicle. This statement was also consistent with previous studies that reported car ownership impacted on the decision $[3,14,36]$.

\section{2) Disaster relative factors}

Experienced a disaster: Respondents who had experienced a disaster were more able to make the decision compared to the inexperienced respondents because their better understanding and perception of a disaster. Based on the analysis, the respondents with experience tended to select their own vehicle $(\beta=-1.386$ in model 1), along with the main reasons that they could safely reach their destination and they were concerned about travel delays with government transportation based on their experience. The literature mentioned that experience of a disaster influenced decision making [34] as experienced persons have a better perception than inexperienced persons with regard to practical decision [3,19,37]. Experience of a disaster and experience of evacuating to shelter were correlated $(r=0.557)$, therefore only one factor (experience of a disaster) was considered in the developed model to avoid multicollinearity issues.

Recognition of shelter location: Respondents who knew the location of the shelter were more likely to take their own vehicle $(\beta=-2.346)$ based on $86 \%$ of the respondents. Therefore, recognition of shelter location could be considered as one of the major factors influencing decision-making on the proposed transport mode.

\section{3) Vehicle Satisfaction factors}

Vehicle satisfaction factors consisted of five factors: (1) safety of evacuees while evacuating ( $\beta=$ 1.531 in model 1), (2) convenience of vehicle access $(\beta=1.023$ in model 1$)$, (3) reaching the destination quickly ( $\beta=0.407$ in model 3 ), (4) proportional family management for evacuation ( $\beta=0.474$ in model 3 ), and (5) ease of the evacuation procedures of mode $(\beta=0.163$ in model 3). All five factors produced results in identical dimensions, as the selected mode decided by the respondents depends on which mode is better supported in the focused factor. For example, regarding safety of evacuees while evacuating, if the respondents decided that the government mode was safer than the private mode, they were more likely to evacuate by the government choice. According to [11,15], vehicle satisfaction factors were associated with decision-making in that they reflected transport service quality, indicating that the government mode should be regarded based on these five factors in order to enhance the transportation system for future disasters. In addition, the convenience of vehicle access was positively correlated with reaching the destination quickly $(r$ $=0.614)$, proportional family management for evacuation $(r=0.192)$, and ease of the evacuation procedures of the mode $(r=0.337)$, indicating these three factors positively affected the outcome of model 1 , which supported the results for these factors in model 3.

\section{4) Transport system factors}

Difference between travel time of government vehicles and private vehicles: The results indicated that if the government mode travel time was longer than the private mode, the respondents were more likely to choose their own vehicle due to the issues of safety and duration $(\beta=-0.418$ in model $2, \beta=$ 0.464 in model 3) $[28,38]$. Thus, the government should consider the most effective route in order to enhance the government mode. Furthermore, addressing this issue may help to improve the trend toward using the government mode.

Walking time to the assembly point: The assembly point is important because if its location is far away where people live, the tendency to select the government choice may be decreased due to the issues of young and elderly family members $(\beta=-0.211$ in model $2, \beta=-0.167$ in model 3$)$. In addition, the location should be convenient for people to access. Therefore, the assembly point should be considered as one of the important tasks to reinforce the system. 
Difference between number of passenger seats in government vehicles and private vehicles: This factor was not statistically significant in the model (Table 6) in that the crowding in the vehicle was the last priority according to the interviews. Following a disaster, it is usual for evacuees to be told to only take essential items in accordance with the evacuation plan [2] and so this reduces the impact on vehicle capacity. As a result, this factor was not significant.

Table 10. Summary of factors influencing evacuees' selection of government vehicle.

\begin{tabular}{|c|c|}
\hline Factor & Government vehicles will be selected. \\
\hline \multicolumn{2}{|l|}{ 1. Social and economic characteristic factors } \\
\hline$\overline{\text { Sex }}$ & If the household leader is female \\
\hline Household size & If the household has more than 4 members \\
\hline Families with young member & $\begin{array}{l}\text { Household without members younger than } 10 \\
\text { years }\end{array}$ \\
\hline Education level & $\begin{array}{l}\text { If the household leader has lower education level } \\
\text { than secondary level }\end{array}$ \\
\hline Car ownership & If the household has less than 2 private vehicles \\
\hline \multicolumn{2}{|l|}{ 2. Disaster relative factors } \\
\hline Experienced a disaster & Households that had never experienced a disaster \\
\hline Recognition of shelter location & $\begin{array}{l}\text { Households that don't know the location of the } \\
\text { shelter }\end{array}$ \\
\hline \multicolumn{2}{|l|}{ 3. Vehicle Satisfaction factors } \\
\hline Safety of evacuees while evacuating & If the government vehicles are safer \\
\hline Convenience of vehicle access & If government vehicles are more convenient \\
\hline Reaching the destination quickly & If the government vehicles are faster \\
\hline Proportional family management for evacuation & If government vehicles can manage better \\
\hline Ease of the evacuation procedures of mode & If government vehicles are easier to use \\
\hline \multicolumn{2}{|l|}{ 4. Transport system factors } \\
\hline Difference between travel time & $\begin{array}{l}\text { If government vehicles spend less time traveling } \\
\text { than private vehicle }\end{array}$ \\
\hline Walking time to the assembly point & If the time to walk to the assembly point decreased \\
\hline
\end{tabular}

The pseudo $\mathrm{R}^{2}$ of the three models were $0.405,0.261$, and 0.325 , respectively. It is noteworthy that the three models had different values of $\mathrm{R}^{2}$ due to the different independent factors considered in each constructed model. Model 1 was constructed based on the respondent's characteristic, model 2 was developed based on the transport system factor obtained from assumed situations, and model 3 was constructed aggregating the factors from models 1 and 2 . However, the authors believe that all three constructed models are acceptable according to their performance (pseudo $\mathrm{R}^{2}>0.2$ ).

\section{Conclusions and recommendation}

This research developed a model for choosing the evacuation travel mode between government vehicles and private vehicles using binary logistic regression analysis. The factors influencing the travel model choice between government vehicles and private vehicles in all 3 models covering 4 categories and 14 factors were: sex, household size, families with young members, education, car ownership, experienced a disaster, recognition of shelter location, safety of evacuees while evacuating, reaching the destination quickly, convenience of vehicle access, proportional family management for evacuation, ease of the evacuation procedures of mode, difference between travel time, and walking time to the assembly point. Considering the sign in front of the parameters of each factor showed that sex, families with young members, education, car ownership, experienced a disaster, recognition of shelter location, the difference between travel time, and walking time to the assembly point were negatively correlated with choosing a government vehicle. This indicated that if the value of these factors increased, the evacuees' satisfaction of travel mode choice by government vehicles would decrease. The factors of household size, safety of evacuees while evacuating, reaching the destination quickly, convenience of vehicle access, proportional family management for evacuation, and ease of the evacuation procedures of mode had a positive relationship with government 
mode choice, which meant that if the government vehicles managed the transportation system better than private cars, evacuees would prefer to select government vehicles for evacuation.

All models in this study can be used to forecast the proportion of travel mode choice for evacuation, which would be useful for government agencies and other relevant agencies as a guide in managing and planning disaster evacuation in the future. Government agencies may further investigate in-depth details of the significant factors revealed in this study to enhance disaster management in order to prevent loss of material and life. In addition, government agencies should instruct villagers on how to best prepare regarding disaster management.

This study can be expanded by including other factors that influence the evacuation decision behavior of households in the intended area to strengthen the reliability of the constructed model. The literature mentioned other influence factors that might be necessary to formulate the prediction model such as number of years living in the residence, house ownership, number of house floor levels, type of material used to construct the house, distance from the source of flood hazard, destination type, presence of health problem, and flood level $[10,32,33]$. In addition, the current authors also believe that there are some potential factors related to decision-making in the context of flooding and landslides. The recommendation is that the future investigation should consider some potential factors in order to enhance the current body of knowledge such as perception of an evacuation alarm, number of evacuees in the household, property concerns, travel demand for evacuees while staying at the shelter, duration of stay at the shelter, and the space in the vehicle for evacuees' belonging.

\section{Acknowledgements}

The researcher expresses her gratitude for the support from her advisor, Asst. Prof. Nipawan Kunsuwan, Ph.D. and would like to thank all respondents for participating. This research was supported by the Department of Civil Engineering, Faculty of Engineering, Kamphaeng Saen and Faculty of Engineering Kamphaeng Saen, Kasetsart University Kamphaeng Saen Campus, Thailand.

\section{References}

[1] Department of Disaster Prevention and Mitigation, DDPM, "Action plan for disaster prevention and mitigation of Mae Poo Subdistrict Administrative Organization," Mae Poo Subdistrict Administrative Organization, Uttaradit, Thailand, Rep. 1, 2017.

[2] Department of Mineral Resources. (2013). Report Risk of Landslide Community at Mae Phun Sub-District, Laplae District, Uttaradit Province [Online]. Available: http://www.dmr.go.th/download/map 57/utharadit/\%E0\%B8\%A3\%E0\%B8\%B2\%E0\%B8\%A2\%E $0 \% \mathrm{~B} 8 \% 87 \% \mathrm{E} 0 \% \mathrm{~B} 8 \% \mathrm{~B} 2 \% \mathrm{E} 0 \% \mathrm{~B} 8 \% 99 \% \mathrm{E} 0 \% \mathrm{~B} 8 \% \mathrm{~A} 3 \% \mathrm{E} 0 \% \mathrm{~B} 8 \% \mathrm{~B} 0 \% \mathrm{E} 0 \% \mathrm{~B} 8 \% 94 \% \mathrm{E} 0 \% \mathrm{~B} 8 \% \mathrm{~B} 1 \%$ $\mathrm{E} 0 \% \mathrm{~B} 8 \% 9 \mathrm{~A} \% \mathrm{E} 0 \% \mathrm{~B} 8 \% 95 \% \mathrm{E} 0 \% \mathrm{~B} 8 \% \mathrm{~B} 3 \% \mathrm{E} 0 \% \mathrm{~B} 8 \% 9 \mathrm{~A} \% \mathrm{E} 0 \% \mathrm{~B} 8 \% \mathrm{~A} 5 \% 20 \% \mathrm{E} 0 \% \mathrm{~B} 8 \% 95 \% \mathrm{E} 0 \% \mathrm{~B} 8$ $\% \mathrm{~B} 3 \% \mathrm{E} 0 \% \mathrm{~B} 8 \% 9 \mathrm{~A} \% \mathrm{E} 0 \% \mathrm{~B} 8 \% \mathrm{~A} 5 \% \mathrm{E} 0 \% \mathrm{~B} 9 \% 81 \% \mathrm{E} 0 \% \mathrm{~B} 8 \% \mathrm{~A} 1 \% \mathrm{E} 0 \% \mathrm{~B} 9 \% 88 \% \mathrm{E} 0 \% \mathrm{~B} 8 \% 9 \mathrm{E} \% \mathrm{E} 0 \%$ B8\%B9\%Е0\%B8\%A5\%20\%E0\%B8\%88\%E0\%B8\%B1\%E0\%B8\%87\%E0\%B8\%AB $\%$ E0 $\%$ B $8 \%$ A7 $\% \mathrm{E} 0 \% \mathrm{~B} 8 \% \mathrm{~B} 1 \% \mathrm{E} 0 \% \mathrm{~B} 8 \% 94 \% \mathrm{E} 0 \% \mathrm{~B} 8 \% \mathrm{AD} \% \mathrm{E} 0 \% \mathrm{~B} 8 \% \mathrm{~B} 8 \% \mathrm{E} 0 \% \mathrm{~B} 8 \% 95 \% \mathrm{E} 0 \% \mathrm{~B} 8 \% \mathrm{~A} 3 \% \mathrm{E} 0 \% \mathrm{~B} 8 \%$ $94 \% \mathrm{E} 0 \% \mathrm{~B} 8 \% \mathrm{~B} 4 \% \mathrm{E} 0 \% \mathrm{~B} 8 \% 95 \% \mathrm{E} 0 \% \mathrm{~B} 8 \% 96 \% \mathrm{E} 0 \% \mathrm{~B} 9 \% 8 \mathrm{C} . p d f$ [Accessed: 29 September 2017]

[3] M. K. Lindell, J. E. Kang, and C. S. Prater, "The logistics of household hurricane evacuation," Nat. Hazards, vol. 58, no. 3, pp. 1093-1109, Jan. 2011.

[4] Z. I. Rao, K. Khan, S. Jafri, and K. Sheeraz, "Public transportation improvement validation model for Metropolitan City Karachi,” Engineering Journal, vol. 18, no. 1, pp. 55-64, May 2013.

[5] N. Eung and K. Choocharukul, "Modeling frequency of using informal public transport and public bus: A case study in Phnom Penh, Cambodia," Engineering Journal, vol. 22, no. 3, pp. 109-122, Jun. 2018.

[6] M. Wachs, "Consumer attitudes toward transit service: An interpretive review," Journal of the American Institute of Planners, vol. 42, no. 1, pp. 96-104, Jan. 1976.

[7] V. A. Tuan and I. B. Mateo-Babiano, "Motorcycle taxi service in Vietnam - Its socioeconomic impacts and policy considerations," Journal of the Eastern Asia Society for Transportation Studies, vol. 10, pp. 13-28, Dec. 2013.

[8] C. Kedsadaporn and S. Siradol, "A feasibility study of peakhour vehicle-trips reduction by kiss and ride facility implementation," Srinakharinwirot Engineering Journal, vol. 1, no. 1, pp. 1-4, Jun. 2012. 
[9] K. Anupon and S. Viroat, "Analysis of factors affecting the transport modes: A case study of KMUTT Bangkuntien Campus," in Queen Sirikit National Convention Center, Bangkok, Thailand, 2010.

[10] H. R. Lim, M. B. B. Lim, and M. Piantanakulchai, "Determinants of household flood evacuation mode choice in a developing country," Nat. Hazards, vol. 84, no. 1, pp. 507-532, Jun. 2016.

[11] A. M. Sadri, S. V. Ukkusuri, P. Murray-Tuite, and H Gladwin, "Analysis of hurricane evacuee mode choice behavior," Transp Res Part C, vol. 48, pp. 37-46, Nov. 2014.

[12] P. Murray-Tuite and B. Wolshon, "Evacuation transportation modeling: An overview of research, development, and practice," Transp Res Part C, vol. 27, pp. 25-45, Feb. 2013.

[13] D. Deka and J. Carnegie, "Analyzing evacuation behavior of transportation-disadvantaged populations in Northern New Jersey," in Transportation Research Board 89th Annual Meeting. Washington DC., U.S., 2010, pp. 10-1584.

[14] M. K. Lindell and C. S. Prater, "Critical behavioral assumptions in evacuation time estimate analysis for private vehicles: Examples from hurricane research and planning," J Urban Plan Dev, vol. 133, no. 1, pp. 18-29, Mar. 2007.

[15] R. Bian, C. G. Wilmot, R. Gudishala, and E. J. Baker, "Modeling household-level hurricane evacuation mode and destination type joint choice using data from multiple post-storm behavioral surveys," Transp Res Part C, vol. 99, pp. 130-143, Feb. 2019.

[16] H. C. Wu, M. K. Lindell, and C. S. Prater, "Logistics of hurricane evacuation in Hurricanes Katrina and Rita," Transp Res Part F, vol. 15, no. 4, pp. 445-461, Jul. 2012.

[17] H. C. Wu, M. K. Lindell, C. S. Prater, and S. K. Huang, "Logistics of hurricane evacuation in Hurricane Ike," in Logistics: Perspectives, Approaches and Challenges. NY: Hauppauge, 2013, ch. 6, pp. 127-140.

[18] M. B. Lim, H.Jr. Lim, and M. Piantanakulchai, "Factors affecting evacuation decision and its implication to transportation planning," J. East Asia Soc. Transp. Stud., vol. 10, pp. 163-177, Dec. 2013.

[19] W. Yin, P. Murray-Tuite, and H. Gladwin, "Statistical analysis of the number of household vehicles used for Hurricane Ivan evacuation," J. Transp. Eng., vol. 140, no. 12, Dec. 2014.

[20] Q. Li, Y. Ooeda, C. Matsunaga, and T. Sumi, "Identifying the determinants of commuting travel mode choice from daily commutation behavior," Memoirs of the Faculty of Engineering, Kyushu University, vol. 62, no. 4, Dec. 2002.

[21] W. Wang and M. Namgung, "Knowledge discovery from the data of long distance travel mode choices based on rough set theory," International Journal of Multimedia and Ubiquitous Engineering, vol. 2, no. 3, pp. 81-90, Jul. 2007.

[22] J. Sajjakaj, L. Thirayoot, and S. Arthit, "Development of mode choice model and vehicle kilometer of travel model for Nakhon Ratchasima Municipality," in The 13th National Graduate Research Conference, Chiang Mai, Thailand, 2009.

[23] T. Fukuda, S. Kashima, A. Fukuda, and S. Narupiti., "Analysis of car sharing application on consumer orientation and their modal selection in Bangkok," Journal of the Eastern Asia Society for Transportation Studies, vol. 6, pp. 1971-1986, Apr. 2005.

[24] R. Wiroj, Urban Transportation Planning, $2^{\text {nd }}$ ed. Bangkok, Thailand: Kasetsart University, 2001, ch. 8, sec. 2, pp. 361-399.

[25] M. Danaf, M. Abou-Zeid, and I. Kaysi., "Modeling travel choices of students at a private, urban university: Insights and policy implications," Case Studies on Transport Policy, vol. 2, no. 3, pp. 142-152, Dec. 2014.

[26] G. Akar, C. Flynn and M. Namgung., "Travel choices and links to transportation demand management case study at Ohio State University," Transportation Research Record Journal of the Transportation Research Board, vol. 2319, no. 1, pp. 77-85, Dec. 2012.

[27] M. P. De Guzman, C. E. Diaz, and P. D. Baguio City, "Analysis of mode choice behavior of students in exclusive schools in Metro Manila: The case of Ateneo De Manila University \& Miriam College," in Proceedings of the Eastern Asia Society for Transportation Studies, 2005, pp. 1116-1131.

[28] S. Suppakorn and L. Paramet., "Development of mode choice models between private vehicles and university bus service in Prince of Songkla," in The 19th National Convention on Civil Engineering, Khon Kaen, Thailand, 2014

[29] A. Tangphaisankun, F. Nakamura, and T. Okamura, "Influences of paratransit as a feeder of mass transit system in developing countries based on commuter satisfaction," in Proceedings of the Eastern Asia Society for Transportation Studies, 2009, pp. 236-236. 
[30] S. P. Washington, M. G. Karlaftis, and F. Mannering, Statistical and Econometric Methods for Transportation Data Analysis, $2^{\text {nd }}$ ed. Florida, USA: Chapman and Hall/CRC, 2010, ch. 12-15, sec. 3, pp. 303-372.

[31] M. E. Ben-Akiva, S. R. Lerman, and S. R. Lerman, Discrete Choice Analysis: Theory and Application to Travel Demand, 9th ed. Cambridge, MA: MIT press, 1985, ch. 4-5, sec. 1-8, pp. 59-129.

[32] M. B. B. Lim, H. R. Lim, M. Piantanakulchai, and F. A. Uy, "A household-level flood evacuation decision model in Quezon City, Philippines," Nat. Hazards, vol. 80, no. 3, pp. 1539-1561, Feb. 2015.

[33] M. B. B. Lim, H. R. Lim, and M. Piantanakulchai, "Flood evacuation decision modeling for high risk urban area in the Philippines," in Proceedings of the 3rd International Conference on Evacuation Modeling and Management (ICEM 2015), Tainan, Taiwan, 2015, pp. 15.

[34] N. Dash and H. Gladwin, "Evacuation decision making and behavioral responses: Individual and household," Nat. Hazards Rev., vol. 8, no. 3, pp. 69-77, Aug. 2007.

[35] J. Sorensen, "Hazard warning systems: review of 20 years of progress," Nat. Hazards Rev., vol. 1, no. 2, pp. 119-125, May 2000.

[36] L. Siebeneck and T. Cova, "An assessment of the return-entry process for Hurricane Rita 2005," IJMED, vol. 26, no. 2, pp. 91-111, Aug. 2008.

[37] S. P. Simonovic and S. Ahmad, "Computer-based model for flood evacuation emergency planning," Nat. Hazards, vol. 34, no. 1, pp. 25-51, Jan. 2005.

[38] D. H. Li and W. G. Hua, "Disaggregate logit model of public transportation share ratio prediction in urban city," in ICCIC 2011, Wuhan, China, 2011, pp. 157-165. 